Revista Complutense de Educación

ISSNe: 1988-2793

https://dx.doi.org/10.5209/rced.63394

\title{
Blockchain en Educación. Cadenas rompiendo moldes
}

Editores: Antonio Bartolomé y José Manuel Moral-Ferrer

Editorial: LMI (Barcelona)

Año de publicación: 2018

$N^{o}$ de páginas: 211

ISBN: 978-84-09-02816-0

Blockchain en Educación es una colección de textos, de los investigadores internacionales más destacados, que explica qué es y para qué se está utilizando la tecnología blockchain (en adelante, BC) en el ámbito educativo. Se exponen casos de aplicación diversos y se analizan las consecuencias de su incorporación en el ámbito educativo.

Estructurado en once capítulos, en primer lugar proporciona una introducción completa para comprender las características de $\mathrm{BC}$ y algunas de sus aplicaciones, para posteriormente adentrarse en las posibilidades que se vislumbran tanto desde una mirada general como académica y finalmente aportar la visión crítica a su incorporación en el ámbito educativo.

En el primer capítulo, los editores ofrecen una marco introductorio a la tecnología y a sus aplicaciones en educación, haciendo énfasis en la comprensión de las características de $\mathrm{BC}$, a la vez que se incorporan ejemplos internaciones de aplicación. Asimismo apuntan $\mathrm{BC}$ como solución a los problemas existentes sobre la acreditación de competencias y saberes, así como la individualización de itinerarios de aprendizaje.

En el segundo capítulo, Don Tapscott y Alex Tapscott (The Tapscott Group Inc.), con una mirada externa al ámbito académico, apuntan las posibilidades de $\mathrm{BC}$ relacionadas con la educación en un ámbito global, no recluida en instituciones locales. Sostienen que BC no es una tecnología o recurso más sino que puede representar un cambio de paradigma en la distribución y validación de contenidos: identificación de estudiantes, acreditación de logros, una nueva pedagogía basada en la adaptación de los aprendizajes...

En el tercer capítulo, Andreia Inamorato dos Santos (Centro Común de Investigación - JRC, Comisión Europea), en contraste con el capítulo anterior, nos aproxima a la realidad actual de $\mathrm{BC}$ desde una mirada académica, especialmente la relacionada con la emisión de certificados digitales. Expone la importancia de la implementación de Blockcerts (estándar abierto para la verificación de certificados académicos) y apunta como el MIT o la Universidad de Nicosia han introducido BC.

Precisamente en los dos siguientes capítulos, los responsables de ambos proyectos pioneros glosan su experiencia.

En el cuarto capítulo, Vasilis Koulaidis (Universidad de Nicosia), a partir de la implementación desarrollada en su universidad, analiza como BC puede ser considerada una herramienta pedagógica, en tanto que incide en procesos de aprendizaje y certificación, en el diseño curricular y en el desarrollo de materiales. 
En el quinto capítulo J. Philipp Schmidt (MIT Media Lab Learning) describe su desarrollo, sobre el cual destaca el valor de poder certificar y listar los logros académicos, que pueden ser compartidos de forma voluntaria y segura con un empleador, por ejemplo.

En el sexto capítulo Mike Sharples (Institute of Educational Technology, The Open University) y John Domingue (Knowledge Media Institute, The Open University) proponen un sistema de registro que proporciona reputación a sus certificados. El conocimiento generaría una especie de bolsa de moneda intelectual que podría fluctuar en base a la reputación. Una estrategia que permitiría ampliar y democratizar el concepto de reputación extramuros de la comunidad académica.

En el séptimo capítulo, Natalie Smolenski y Kim Hamilton Duffy (Learning Machine) defienden la necesidad de trabajar con estándares abiertos que posibiliten trabajar e integrar diversos proyectos. Un caso es Blockcerts, un bloque que permite documentar títulos y certificados académicos en BC.

En el octavo capítulo, Marcelo Brito Carneiro Leão y Carolina Guimarães Raposo (Universidade Federal Rural de Pernambuco, Brasil) muestran las posibilidades de $\mathrm{BC}$ en la gestión universitaria, vinculadas con la identificación, la seguridad y el intercambio (tratamiento) de la información: desburocratización de procesos, intercambio ágil de información o creación de identidades digitales para el acceso a servicios.

En el noveno capítulo, Antonio Bartolomé (Universidad de Barcelona) presenta el proyecto Edu-blockchain, una propuesta de individualización de aprendizajes sustentada por $\mathrm{BC}$ en que se generan itinerarios personalizados para los alumnos.

Los dos últimos capítulos inciden en la mirada crítica ante el advenimiento de BC.

En el décimo capítulo, Audrey Watters (escritora especializada en tecnología educativa) remarca los aspectos ideológicos que subyacen en la tecnología, que son incorporados en sus ámbitos de usos. Como la descentralización de datos en educación incorpora una mirada neoliberal global.

En el capítulo final, Jordi Adell y Carles Bellver (Universitat Jaume I) alzan la mirada crítica sobre las expectativas exageradas creadas alrededor de la tecnología en general y $\mathrm{BC}$ en particular, así como la tendencia al determinismo tecnológico y la ideología subyacente que convierte la educación en un sistema de mercado.

Para un educador sin conocimientos previos de BC, el libro resulta una buena lectura introductoria para comprender qué es, cómo funciona y cómo incide en aspectos educativos, especialmente teniendo en cuenta la cantidad de información dispersa que sobre el tema se produce. Adquirirá una mirada clara y ordenada sobre el estado actual del uso de BC, atendiendo a sus orígenes y a las posibilidades futuras.

Para un lector con conocimientos sobre la tecnología, se le ofrece un análisis completo y profundo de las aplicaciones desarrolladas, a la vez que una visión crítica sobre la implantación de BC.

El volumen es especialmente relevante por ser el primero publicado en español que ofrece tal cantidad y calidad de información sobre BC aplicado a la educación. Una tecnología llamada a representar un cambio en el uso de las bases de datos, sobre el cual es difícil prever todas las consecuencias en su incorporación en las aulas.

Carles Lindín Soriano

Universidad de Barcelona carles.lindin@ub.edu

Pablo Rivera-Vargas pablorivera@ub.edu

Universidad de Barcelona Universidad Andrés Bello (Chile) 